\title{
Polarized arrest with warm or cold adenosine/lidocaine blood cardioplegia is equivalent to hypothermic potassium blood cardioplegia
}

\author{
Joel S. Corvera, MD \\ Hajime Kin, MD, $P h D^{\text {a }}$ \\ Geoffrey P. Dobson, PhD \\ Faraz Kerendi, MDa \\ Michael E. Halkos, MD \\ Sara Katzmark, BS ${ }^{a}$ \\ Christopher S. Payne, BS ${ }^{a}$ \\ Zhi-Qing Zhao, MD, $\mathrm{PhD}^{\mathrm{a}}$ \\ Robert A. Guyton, MD ${ }^{\mathrm{a}}$ \\ Jakob Vinten-Johansen, $\mathrm{PhD}^{\mathrm{a}}$
}

From the Cardiothoracic Research Laboratory and Carlyle Fraser Heart Center, Emory University School of Medicine, Atlanta, $\mathrm{Ga}^{\mathrm{a}}{ }^{\mathrm{a}}$ and the Department of Physiology and Pharmacology, James Cook University, Townsville, Queensland, Australia. ${ }^{\mathrm{b}}$

Received for publication Aug 3, 2003; revisions received June 21, 2004; accepted for publication July 9, 2004.

Address for reprints: Jakob Vinten-Johansen, $\mathrm{PhD}$, Cardiothoracic Research Laboratory, Emory University School of Medicine, 550 Peachtree St, NE, Atlanta, GA 30308 (E-mail: jvinten@emory.edu).

J Thorac Cardiovasc Surg 2005;129: $599-606$

$0022-5223 / \$ 30.00$

Copyright (C) 2005 by The American Association for Thoracic Surgery

doi:10.1016/j.jtcvs.2004.07.021
Background: Hypothermic depolarizing hyperkalemic $\left(\mathrm{K}^{+} 20 \mathrm{mEq} / \mathrm{L}\right)$ blood cardioplegia is the "gold standard" in cardiac surgery. $\mathrm{K}^{+}$has been associated with deleterious consequences, eg, intracellular calcium overload. This study tested the hypothesis that elective arrest in a polarized state with adenosine $(400 \mu \mathrm{mol} / \mathrm{L}$ via adenosine triphosphate-sensitive potassium channel opening) and the $\mathrm{Na}^{+}$channel blocker lidocaine $(750 \mu \mathrm{mol} / \mathrm{L})$ as the arresting agents in blood cardioplegia provides cardioprotection comparable to standard hypothermic $\mathrm{K}^{+}$-blood cardioplegia.

Methods: Anesthetized dogs were placed on cardiopulmonary bypass and assigned to 1 of 3 groups receiving antegrade cardioplegia delivered every 20 minutes for 1 hour of arrest: cold $\left(10^{\circ} \mathrm{C}\right) \mathrm{K}^{+}$-blood cardioplegia $(\mathrm{n}=6)$, cold $\left(10^{\circ} \mathrm{C}\right)$ adenosine/lidocaine blood cardioplegia $(\mathrm{n}=6)$, or warm $\left(37^{\circ} \mathrm{C}\right)$ adenosine/lidocaine blood cardioplegia $(n=6)$. After an hour of arrest, cardiopulmonary bypass was discontinued, and reperfusion was continued for 120 minutes.

Results: Time to arrest was longer with cold and warm adenosine/lidocaine blood cardioplegia (175 \pm 19 seconds and $143 \pm 19$ seconds, respectively) compared with $\mathrm{K}^{+}$-blood cardioplegia $(27 \pm 2$ seconds; $P<.001)$. Postcardioplegia left ventricular systolic function (slope of the end-systolic pressure/dimension relationship) was comparable among the 3 groups $\left(\mathrm{K}^{+}\right.$-blood cardioplegia, $15.2 \pm$ $2.1 \mathrm{~mm} \mathrm{Hg} / \mathrm{mm}$; cold adenosine/lidocaine blood cardioplegia, $15.9 \pm 3.4 \mathrm{~mm}$ $\mathrm{Hg} / \mathrm{mm}$; warm adenosine/lidocaine blood cardioplegia, $14.1 \pm 2.8 \mathrm{~mm} \mathrm{Hg} / \mathrm{mm}$; $P=.90)$. Plasma creatine kinase activity in cold and warm adenosine/lidocaine blood cardioplegia was similar to that in $\mathrm{K}^{+}$-blood cardioplegia at 120 minutes of reperfusion (cold adenosine/lidocaine blood cardioplegia, $11.5 \pm 2.1 \mathrm{IU} / \mathrm{g}$ protein; warm adenosine/lidocaine blood cardioplegia, $10.1 \pm 0.9 \mathrm{IU} / \mathrm{g}$ protein; $\mathrm{K}^{+}$-blood cardioplegia, $7.6 \pm 0.8 \mathrm{IU} / \mathrm{g}$ protein; $P=.17$ ). Postcardioplegia coronary artery endothelial function was preserved in all groups.

Conclusions: Intermittent polarized arrest with warm or cold adenosine/lidocaine blood cardioplegia provided the same degree of myocardial protection as intermittent hypothermic $\mathrm{K}^{+}$-blood cardioplegia in normal hearts. 


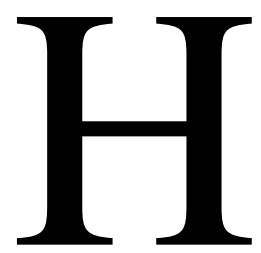

yperkalemic cardioplegia is the "gold standard" method to arrest the heart. A high potassium concentration depolarizes the myocyte membrane and induces electromechanical arrest. Hypothermia is also frequently used for intermittent cardioplegia. However, there are disadvantages to using both depolarizing potassium cardioplegia and hypothermia, especially in severely injured hearts. Membrane depolarization with potassium is associated with continued ion exchange across the cell membrane through sodium and calcium "window currents," intracellular sodium and calcium overload, ${ }^{1}$ continued energy expenditure, and cardiomyocyte dysfunction and death. ${ }^{2}$ To counter the increased energy expenditure, hypothermia effectively reduces oxygen demand but causes membrane instability, edema, arrhythmias, and slows the metabolic and functional recovery of the postischemic myocyte. $^{3,4}$

An alternative approach to arresting the heart is to maintain the transmembrane electrical potential in a polarized state ${ }^{5}$ which locks the ion channels in a "closed" state. Therefore, ionic imbalances and subsequent consequences are likely to be avoided. ${ }^{5}$ Adenosine triphosphate-sensitive potassium channel opening (PCO) agents (eg, nicorandil and aprikalim) have been used to achieve polarized or hyperpolarized arrest. ${ }^{6,7}$ However, PCO agents have been reported to increase postischemic arrhythmias ${ }^{8}$ and myocardial oxygen demand on reperfusion and to produce profound systemic hypotension. For these reasons, hyperpolarized arrest with PCO agents as the arresting agent has not been adopted as a clinical cardioplegia strategy.

The combination of adenosine and lidocaine is an alternative method to achieve polarized arrest. ${ }^{9}$ Adenosine activates adenosine triphosphate-sensitive potassium channels by $\mathrm{A}_{1}$-receptor-mediated mechanisms. ${ }^{10,11}$ Lidocaine, a widely used local anesthetic, prevents transmembrane depolarization and electrical activation by blocking sodium channels. The combination of lidocaine and adenosine induces polarized arrest in either a normothermic or hypothermic environment ${ }^{9,12}$ and may therefore offer an alternative method of inducing cardioplegia. This study tested the hypothesis that polarized arrest with normothermic or hypothermic adenosine/lidocaine blood cardioplegia (AL$\mathrm{BCP}$ ) provides similar cardioprotection to the gold standard hypothermic depolarizing hyperkalemic blood cardioplegia $\left(\mathrm{K}^{+}-\mathrm{BCP}\right)$ in normal myocardium when used in a canine model of cardiopulmonary bypass (CPB).

\section{Materials and Methods}

All animals received humane care in compliance with the "Guide for the Care and Use of Laboratory Animals" prepared by the Institute of Laboratory Animal Resources, National Research Council, and published by the National Academy Press (revised 1996). Dogs were premedicated with morphine sulfate $(4 \mathrm{mg} / \mathrm{kg}$
TABLE 1. Blood cardioplegia volumes and myocardial temperatures

\begin{tabular}{|c|c|c|c|}
\hline Variable & Volume (mL) & Ant $\mathrm{T}\left({ }^{\circ} \mathrm{C}\right)$ & Post $\mathrm{T}\left({ }^{\circ} \mathrm{C}\right)$ \\
\hline \multicolumn{4}{|l|}{ ВCP1 } \\
\hline Warm AL-BCP & $1084 \pm 70$ & $34.6 \pm 0.5$ & $35.1 \pm 0.4$ \\
\hline Cold AL-BCP & $643 \pm 31^{*}$ & $18.3 \pm 0.8^{*}$ & $15.9 \pm 0.7^{*}$ \\
\hline $\mathrm{K}^{+}-\mathrm{BCP}$ & $595 \pm 85^{*}$ & $18.4 \pm 1.2^{*}$ & $15.9 \pm 1.0^{*}$ \\
\hline \multicolumn{4}{|l|}{ BCP2 } \\
\hline Warm AL-BCP & $379 \pm 26$ & $32.6 \pm 0.5$ & $33.9 \pm 0.4$ \\
\hline Cold AL-BCP & $274 \pm 32$ & $18.8 \pm 0.4^{*}$ & $17.4 \pm 0.5^{*}$ \\
\hline $\mathrm{K}^{+}-\mathrm{BCP}$ & $480 \pm 76^{*} \dagger$ & $16.5 \pm 1.2^{*} \dagger$ & $14.1 \pm 1.1^{*} \dagger$ \\
\hline \multicolumn{4}{|l|}{ BCP3 } \\
\hline Warm AL-BCP & $387 \pm 21$ & $33.1 \pm 0.5$ & $34.3 \pm 0.4$ \\
\hline Cold AL-BCP & $284 \pm 29$ & $19.4 \pm 0.5^{*}$ & $18.0 \pm 0.8^{*}$ \\
\hline $\mathrm{K}^{+}-\mathrm{BCP}$ & $500 \pm 79 * \dagger$ & $16.3 \pm 0.8^{*} \dagger$ & $15.2 \pm 0.8^{*} \dagger$ \\
\hline \multicolumn{4}{|l|}{ BCP4 (hot shot) } \\
\hline Warm AL-BCP & $1246 \pm 45$ & $35.2 \pm 0.2$ & $35.8 \pm 0.1$ \\
\hline Cold AL-BCP & $1104 \pm 64$ & $33.8 \pm 0.4$ & $33.7 \pm 1.3$ \\
\hline $\mathrm{K}^{+}-\mathrm{BCP}$ & $934 \pm 85^{*}$ & $33.1 \pm 0.7^{*}$ & $35.0 \pm 0.3$ \\
\hline \multicolumn{4}{|l|}{ Total BCP volume } \\
\hline Warm AL-BCP & $3096 \pm 163$ & & \\
\hline Cold AL-BCP & $2305 \pm 156$ & & \\
\hline $\mathrm{K}^{+}-\mathrm{BCP}$ & $2508 \pm 325$ & & \\
\hline
\end{tabular}

$A L$, Adenosine/lidocaine; $B C P$, blood cardioplegia; $B C P 1$, induction $B C P$ infusion; $B C P 2$ and $B C P 3$, Intermittent $C P$ infusions; $B C P 4$, terminal $B C P$ infusion; Ant $T$, myocardial temperature in the anterior left ventricle; Post $T$, myocardial temperature in the posterior left ventricle.

$* P<.05$ versus warm AL-BCP.

$\dagger P<.05$ versus cold AL-BCP.

intramuscularly). General anesthesia was induced with sodium pentothal $(20 \mathrm{mg} / \mathrm{kg}$ intravenously [IV]) and maintained by continuous infusion of fentanyl $\left(0.4 \mu \mathrm{g} \cdot \mathrm{kg}^{-1} \cdot \mathrm{min}^{-1}\right)$ and diazepam $\left(3 \mu \mathrm{g} \cdot \mathrm{kg}^{-1} \cdot \mathrm{min}^{-1}\right)$. Nembutal injections $(20-30 \mathrm{mg} / \mathrm{kg}$ IV) were administered as needed for supplemental anesthesia. Dogs were endotracheally intubated and mechanically ventilated (Ohmeda ventilator, BOC Group Inc, Madison, Wis) to maintain a $\mathrm{pH}$ of 7.35 to $7.45, \mathrm{a} \mathrm{Po}_{2}$ of greater than $100 \mathrm{~mm} \mathrm{Hg}$, and a $\mathrm{PCO}_{2}$ of 35 to $45 \mathrm{~mm} \mathrm{Hg}$. A polyethylene catheter was inserted into the right femoral artery to monitor systemic arterial pressure and to sample arterial blood.

The chest was opened via median sternotomy. The pericardium was incised and sutured to form a cradle. Millar MPC-500 (Millar Instruments, Inc, Houston, Tex) solid-state pressure catheters were placed into the left ventricle (LV) via an apical incision and into the aortic arch via the right internal thoracic artery to continuously measure the LV and aortic pressures, respectively. A pair of 2-mm-diameter 10-MHz piezoelectric ultrasonic crystals (Sonometrics Corporation, London, Ontario, Canada) were placed in the subendocardium in the anterior/posterior minor axis of the LV to measure global systolic and diastolic characteristics by pressuredimension loop analysis.

Heparin (300 mg/kg IV) was given and supplemented (150 $\mathrm{mg} / \mathrm{kg}$ IV) every 90 minutes thereafter. The left subclavian artery was cannulated (20F; Baxter Healthcare Corporation, Midvale, Utah) for systemic perfusion, and the right atrium was cannulated 
TABLE 2. Hemodynamic and cardiodynamic characteristics

\begin{tabular}{|c|c|c|c|c|c|c|c|}
\hline Variable & HR (beats/min) & $\begin{array}{l}\text { LV max } \\
(\mathrm{mm} \mathrm{Hg})\end{array}$ & $\begin{array}{l}\text { LV EDP } \\
(\mathrm{mm} \mathrm{Hg})\end{array}$ & $\mathrm{dP} / \mathrm{dt} \max$ & $\begin{array}{l}\text { Ao mean } \\
(\mathrm{mm} \mathrm{Hg})\end{array}$ & ESD (mm) & EDD (mm) \\
\hline \multicolumn{8}{|l|}{ Baseline } \\
\hline Warm AL-BCP & $102.1 \pm 4.5$ & $98.3 \pm 4.5$ & $10.0 \pm 1.4$ & $1065 \pm 51$ & $86.3 \pm 3.7$ & $30.7 \pm 2.6$ & $35.5 \pm 2.5$ \\
\hline Cold AL-BCP & $96.7 \pm 6.7$ & $103.7 \pm 3.2$ & $5.8 \pm 0.9^{*}$ & $1202 \pm 90$ & $86.5 \pm 4.2$ & $33.6 \pm 1.4$ & $39.6 \pm 1.5^{*}$ \\
\hline $\mathrm{K}^{+}-\mathrm{BCP}$ & $102.1 \pm 4.8$ & $105.3 \pm 3.9$ & $7.3 \pm 0.7$ & $1124 \pm 66$ & $90.8 \pm 3.5$ & $31.2 \pm 2.9$ & $37.3 \pm 1.9$ \\
\hline \multicolumn{8}{|l|}{$\mathrm{R} 60$} \\
\hline Warm AL-BCP & $145.1 \pm 3.3 \dagger$ & $91.2 \pm 5.5 \dagger$ & $8.5 \pm 2.0$ & $955 \pm 43 \dagger$ & $75.8 \pm 5.9 \dagger$ & $33.2 \pm 2.1$ & $36.0 \pm 2.2$ \\
\hline Cold AL-BCP & $129.2 \pm 8.2 \dagger$ & $96.2 \pm 1.7$ & $5.2 \pm 0.8$ & $1024 \pm 68 \dagger$ & $76.2 \pm 3.2 \dagger$ & $35.2 \pm 1.4$ & $39.8 \pm 1.5$ \\
\hline $\mathrm{K}^{+}-\mathrm{BCP}$ & $141.9 \pm 3.5 \dagger$ & $93.2 \pm 4.0 \dagger$ & $6.9 \pm 0.8$ & $968 \pm 80 \dagger$ & $76.4 \pm 4.6 \dagger$ & $32.4 \pm 2.8$ & $36.1 \pm 2.2$ \\
\hline \multicolumn{8}{|l|}{ R90 } \\
\hline Warm AL-BCP & $143.7 \pm 6.1 \dagger$ & $88.7 \pm 3.3 \dagger$ & $8.0 \pm 1.6$ & $925 \pm 43 \dagger$ & $74.8 \pm 3.6 \dagger$ & $33.2 \pm 2.2$ & $36.3 \pm 2.3$ \\
\hline Cold AL-BCP & $119.6 \pm 7.1^{*} \dagger$ & $95.6 \pm 3.7$ & $5.9 \pm 0.6$ & $927 \pm 46$ & $75.4 \pm 3.5$ & $35.7 \pm 1.4$ & $40.1 \pm 1.4$ \\
\hline $\mathrm{K}^{+}-\mathrm{BCP}$ & $137.2 \pm 5.9 \dagger$ & $91.9 \pm 2.5 \dagger$ & $6.5 \pm 0.8$ & $906 \pm 51 \dagger$ & $74.4 \pm 3.2 \dagger$ & $32.4 \pm 2.8$ & $35.8 \pm 2.4$ \\
\hline \multicolumn{8}{|l|}{ R120 } \\
\hline Warm AL-BCP & $134.8 \pm 5.6 \dagger$ & $88.3 \pm 2.8 \dagger$ & $8.3 \pm 1.4$ & $854 \pm 45 \dagger$ & $75.3 \pm 2.8 \dagger$ & $33.6 \pm 2.2$ & $36.6 \pm 2.3$ \\
\hline Cold AL-BCP & $119.3 \pm 8.5 \dagger$ & $98.5 \pm 2.5$ & $5.8 \pm 0.9$ & $916 \pm 55 t$ & $80.1 \pm 2.2$ & $36.5 \pm 1.1$ & $40.7 \pm 1.3$ \\
\hline $\mathrm{K}^{+}-\mathrm{BCP}$ & $134.0 \pm 4.9 \dagger$ & $89.7 \pm 3.4 \dagger$ & $6.5 \pm 0.8$ & $833 \pm 44 \dagger$ & $73.5 \pm 4.4 \dagger$ & $32.4 \pm 2.9$ & $35.7 \pm 2.5$ \\
\hline
\end{tabular}

$H R$, Heart rate; $L V \max$, maximal left ventricular pressure; $L V E D P$, left ventricular end-diastolic pressure; $d P / d t$ max, maximal value of the first derivative of left ventricular pressure; Ao mean, aortic mean pressure; $E S D$, end-systolic anterior/posterior minor axis dimension; $E D D$, end-diastolic anterior/posterior minor axis dimension; $R 60,60$ minutes of reperfusion; $R 90,90$ minutes of reperfusion; $R 120,120$ minutes of reperfusion; $A L$, adenosine lidocaine; $B C P$, blood cardioplegia.

$* P<.05$ versus warm AL-BCP,

$\dagger P<.05$ versus baseline within each group by repeated-measures analysis of variance.

with a 2-stage cannula (36/46F; United States Surgical Corporation, Norwalk, Conn) to harvest venous return. A double-lumen DLP cardioplegia cannula (Medtronic, Inc, Minneapolis, Minn) was inserted in the proximal ascending aorta for delivery of BCP, and the LV was vented (20F; United States Surgical Corporation).

CPB was initiated with a membrane oxygenator (Cobe Cardiovascular, Inc, Arvada, Colo). Mean arterial blood pressure during CPB was maintained at $70 \mathrm{~mm} \mathrm{Hg}$ by adjusting the arterial flow rate. The dogs were randomly divided into 3 groups. In the $\mathrm{K}^{+}$-BCP group $(\mathrm{n}=6)$, multidose hyperkalemic BCP (8 parts blood to 1 part crystalloid) was delivered with the Myocardial Protection System (Quest Medical, Inc, Allen, Tex). The crystalloid component contained tromethamine (THAM) $823 \mathrm{mmol} / \mathrm{L}$, sodium $103 \mathrm{mEq} / \mathrm{L}$, citrate $57.5 \mathrm{mEq} / \mathrm{L}$, phosphate $92.5 \mathrm{mEq} / \mathrm{L}$, and dextrose $233 \mathrm{mmol} / \mathrm{L} . \mathrm{K}^{+}$-BCP was delivered with the cold induction modality (3-minute induction infusion at $10^{\circ} \mathrm{C} ; 20$ $\mathrm{mEq} / \mathrm{L} \mathrm{K}^{+}$final concentration), with subsequent infusions made at 20 and 40 minutes at $10^{\circ} \mathrm{C}$ for 2 minutes each $\left(10 \mathrm{mEq} / \mathrm{L} \mathrm{K}^{+}\right)$. The terminal delivery was a modifed "hot shot" $\left(20 \mathrm{mEq} / \mathrm{L} \mathrm{K}^{+}\right){ }^{13}$

In the cold AL-BCP group $(n=6)$, hypothermic $\mathrm{BCP}(22$ parts blood to 1 part crystalloid, ie, minicardioplegia, ${ }^{14}$ with 400 $\mu \mathrm{mol} / \mathrm{L}$ adenosine and $750 \mu \mathrm{mol} / \mathrm{L}$ lidocaine per liter of cardioplegia without other additives) was delivered by the Myocardial Protection System. Adenosine was delivered via a separate line to avoid degradation by adenosine deaminase. Cold AL-BCP was delivered using the cold induction strategy as in the $\mathrm{K}^{+}$- $\mathrm{BCP}$ group. The duration of induction was the greater of 2 minutes or the time necessary to achieve arrest plus an additional 30 seconds. Intermittent infusions of 1 minute each were made at 20 and 40 minutes. After 60 minutes of arrest, a terminal hot shot was delivered for 3 minutes with adenosine but without lidocaine to reduce the overall dose of lidocaine. In the warm AL-BCP group ( $\mathrm{n}=6)$, multidose normothermic BCP $(22: 1)$ with $400 \mu \mathrm{mol} / \mathrm{L}$ adenosine and $750 \mu \mathrm{mol} / \mathrm{L}$ lidocaine was administered at $37^{\circ} \mathrm{C}$ in the same manner as cold AL-BCP. All cardioplegia solutions were infused at a pressure of $50 \mathrm{~mm} \mathrm{Hg}$. The total time of elective arrest was 60 minutes.

Immediately after completion of the terminal cardioplegia delivery, systemic blood pressure was adjusted to $50 \mathrm{~mm} \mathrm{Hg}$, and the aortic crossclamp was removed. After electromechanical reanimation, the perfusion pressure was increased to $80 \mathrm{~mm} \mathrm{Hg}$ over 3 to 5 minutes. The heart was reperfused on $\mathrm{CPB}$ for 30 minutes, after which reperfusion was continued on CPB for 2 hours.

The animals were euthanized with sodium pentobarbital (100 $\mathrm{mg} / \mathrm{kg} \mathrm{IV}$ ) at the end of the experiment. The heart was immediately excised and placed into $4^{\circ} \mathrm{C}$ Krebs-Henseleit buffer $(118 \mathrm{mmol} / \mathrm{L}$ $\mathrm{NaCl}, 4.7 \mathrm{mmol} / \mathrm{L} \mathrm{KCl}, 1.2 \mathrm{mmol} / \mathrm{L} \mathrm{KH}_{2} \mathrm{PO}_{4}, 1.2 \mathrm{mmol} / \mathrm{L} \mathrm{MgSO}_{4}$, $2.5 \mathrm{mmol} / \mathrm{L} \mathrm{CaCl}_{2}, 12.5 \mathrm{mmol} / \mathrm{L} \mathrm{NaHCO}_{3}$, and $10 \mathrm{mmol} / \mathrm{L}$ glucose at $\mathrm{pH}$ 7.4).

\section{Data Acquisition and Analysis}

Analog cardiodynamic and hemodynamic data were digitized and recorded on a personal computer by using SonoView Cardiovascular Acquisition software (Sonometrics Corporation). Data were acquired at baseline (after instrumentation and a brief period of stabilization and before the initiation of CPB) and at 60,90, and 120 minutes after removal of the aortic crossclamp. Data analysis was performed with SPECTRUM cardiovascular data analysis software (Wake Forest University, Winston-Salem, NC). 


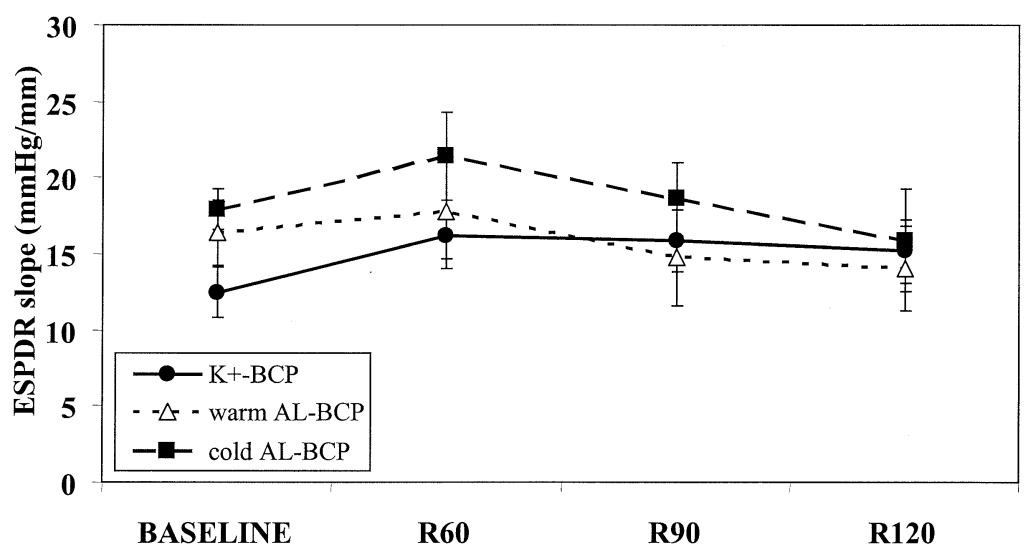

Figure 1. End-systolic pressure/dimension relationship at baseline and during reperfusion. ESPDR, Slope of the end-systolic pressure/dimension relationship during transient caval occlusion, an index of global left ventricular contractility. $R 60, R 90$, and $R 120,60,90$, and 120 minutes of reperfusion, respectively.

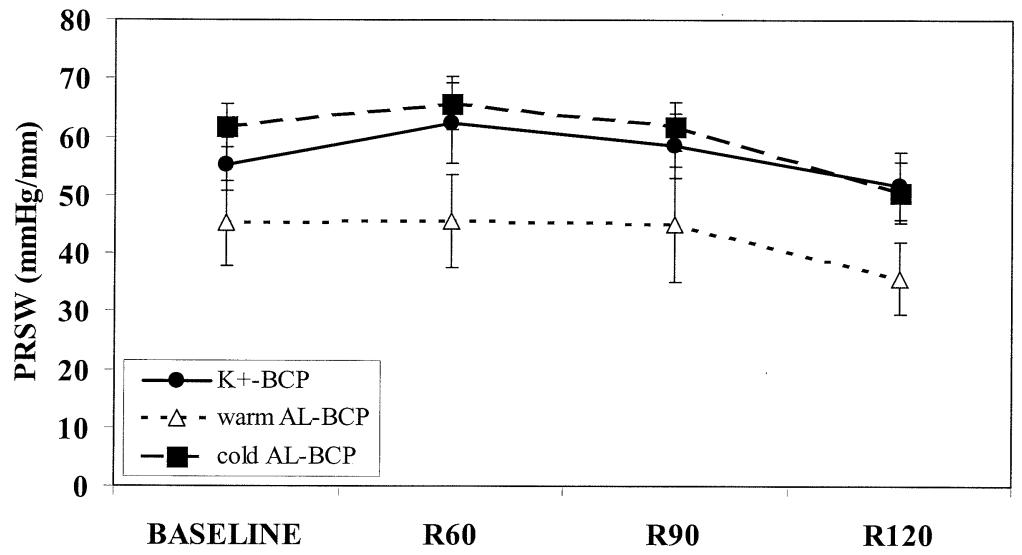

Figure 2. Left ventricular preload recruitable stroke work during baseline and reperfusion, derived from pressure/ minor axis diameter data. PRSW, Preload recruitable stroke work; R60, R90, and R120, 60, 90, and 120 minutes of reperfusion, respectively.

\section{Physiologic End Points}

Global systolic and diastolic function. Global systolic function was quantified by end-systolic pressure/minor axis dimension relations (ESPDR) and preload-recruitable stroke work (PRSW) as previously described. ${ }^{15}$ Global diastolic function was quantified by fitting the declining end-diastolic pressure/diameter points obtained during inferior vena cava occlusion to an exponential curve and calculating the degree of curvature ( $\beta$-coefficient).

Plasma creatine kinase activity. Arterial plasma creatine kinase $(\mathrm{CK})$ levels were taken at baseline, 5 minutes after the institution of CPB, after each BCP delivery, and at 60, 90, and 120 minutes of reperfusion off $\mathrm{CPB}$, and were assayed spectrophotometrically. ${ }^{13}$

Myocardial tissue water content. Tissue water content was determined by 72-hour dessication of transmural LV myocardial biopsy samples taken at the conclusion of the experiment. The percentage of tissue water content was also determined in normal hearts $(\mathrm{n}=6)$ not subjected to CPB, for reference.

Myeloperoxidase activity in myocardium. Myeloperoxidase, an enzyme relatively specific for neutrophils, was determined in the postexperimental myocardium by using a modification of the method of Mullane and colleagues ${ }^{16}$ and was reported as the rate of hydrogen peroxide degradation-induced color change in absorbance units per minute per gram of tissue.

Postexperimental coronary artery endothelial function. The postexperimental left anterior descending coronary artery was isolated from the excised heart to determine vascular endothelial function in organ chambers by using relaxation responses of preconstricted (U46619; $5 \mu \mathrm{mol} / \mathrm{L}$ ) arterial segments to incremental concentrations of endothelium-dependent (acetylcholine, A23187) and -independent (sodium nitroprusside) vasodilators, as described previously. Indomethacin $(10 \mu \mathrm{mol} / \mathrm{L})$ was added to the buffer to inhibit endogenous prostanoids. 


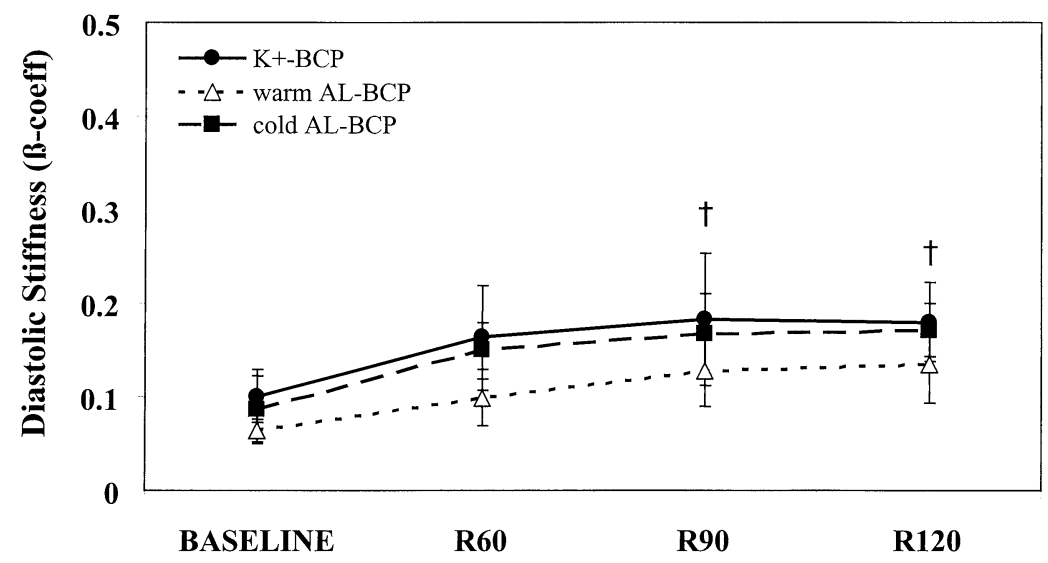

Figure 3. Left ventricular end-diastolic pressure/dimension relationship as a measure of global left ventricular stiffness. $\beta$, Modulus of diastolic stiffness obtained by fitting successive end-diastolic pressure points obtained during transient caval occlusion to a curve, an inverse index of left ventricular compliance; $R 60, R 90$, and $R 120,60$, 90, and 120 minutes of reperfusion, respectively. $t P<.05$ versus baseline values by repeated-measures ANOVA.

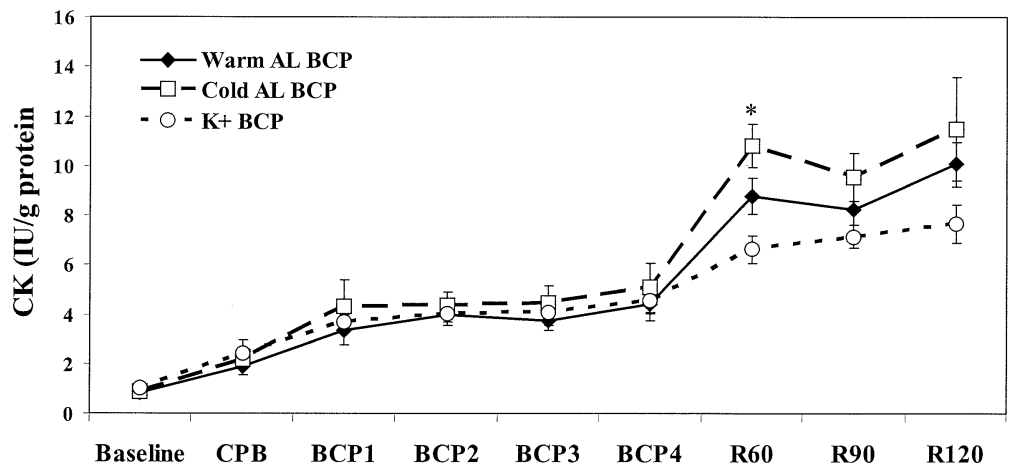

Figure 4. Plasma creatine kinase activity during the course of the experiment. CPB, Sampled 5 minutes after initiation of CPB; $B C P 1$, sampled at the end of the induction BCP infusion; $B C P 2$ and $B C P 3$, sampled at the end of intermittent BCP infusions; $B C P 4$, sampled at the end of terminal $B C P$ infusion; $R 60, R 90$, and $R 120$, sampled at 60 , 90, and 120 minutes of reperfusion, respectively. ${ }^{*} P<.05$ for cold AL-BCP versus $K^{+}-B C P$ at $R 60$.

\section{Statistics}

All data are reported as mean \pm SEM. A 1-way analysis of variance (ANOVA) and ANOVA for repeated measures were used to compare single-point and time-dependent variables in multiple groups, respectively, followed by a post hoc Student-NeumanKeuls test correcting for multiple comparisons to indentify the source of significant differences.

\section{Results}

The induction volume of $\mathrm{K}^{+}$-BCP and cold AL-BCP was significantly less than that in the warm AL-BCP group $(P<$ .05; Table 1). Intermittent infusion volumes of BCP were significantly greater in cold $\mathrm{K}^{+}$-BCP than in the warm AL-BCP and cold AL-BCP groups because the infusion time for the $\mathrm{K}^{+}$-BCP group was 2 minutes, versus 1 minute for the AL-BCP groups. However, there was no significant difference among groups in total cardioplegia volumes. The steady-state hemodynamic profiles of the 3 groups were similar during the course of the experiment (Table 2), with the exception that heart rate was significantly higher in warm AL-BCP versus cold AL-BCP $(P=.045)$ at 120 minutes of reperfusion.

There was no difference between the AL-BCP groups in the duration of the induction infusion (cold, $205 \pm 21$ seconds; warm, $189 \pm 14$ seconds) versus the prescribed 180 seconds in the $\mathrm{K}^{+}$-BCP group. However, the time to mechanical arrest was significantly longer in both the cold AL-BCP and the warm AL-BCP groups (175 \pm 19 seconds and $143 \pm 19$ seconds, respectively) versus the $\mathrm{K}^{+}$-BCP group $(27 \pm 2$ seconds; $P<.001)$. Complete electromechanical arrest was not achieved within the 2-minute time frame in 2 of 6 animals in the cold AL-BCP group. Fur- 


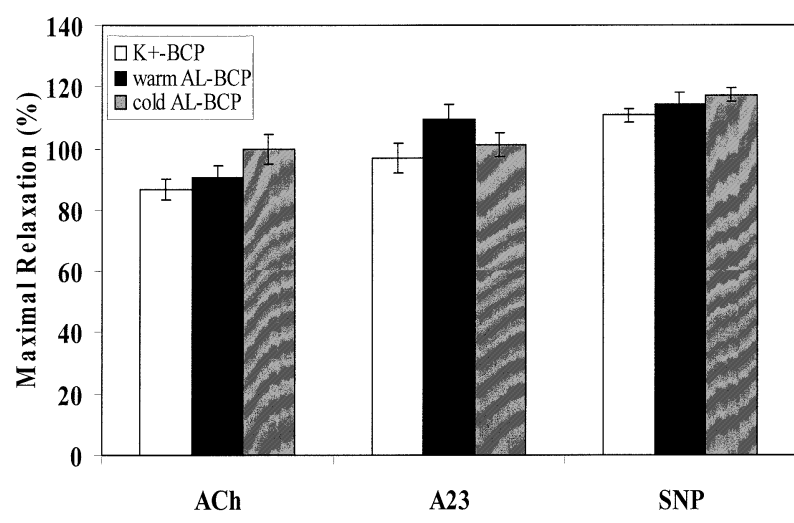

Figure 5. Postexperimental left anterior descending (LAD) coronary artery endothelial and smooth muscle function. Maximal relaxation responses to acetylcholine $(A C h)$, calcium ionophore A23187 (A23), and sodium nitroprusside (SNP) are shown in postexperimentally excised epicardial LAD coronary arteries. Maximum values were determined from stepwise incremental concentrations of each drug.

thermore, breakthrough reanimation was present in 5 of 6 hearts receiving cold AL-BCP.

Ventricular fibrillation during early reperfusion was observed in 1 experiment in each of the cold AL-BCP and warm AL-BCP groups. During the terminal hot shot infusion in which lidocaine was omitted, hearts in the warm and cold AL-BCP groups began to reanimate $86 \pm 15$ seconds and $74 \pm 9$ seconds into infusion, respectively, whereas hearts in the $\mathrm{K}^{+}$-BCP group remained arrested for the duration of the terminal cardioplegia. Hearts in the $\mathrm{K}^{+}$-BCP group reanimated $140 \pm 15$ seconds after removal of the crossclamp, and this was significantly longer than the time to reanimation in the AL-BCP groups during terminal cardioplegia.

The slope of the ESPDR was comparable at baseline in all groups (Figure 1). There was no significant change in the slope of the ESPDR from baseline during any time in reperfusion, and there were no significant group differences at any time during reperfusion. In addition, there was no difference in the PRSW at any time point (Figure 2). The $\beta$-coefficient of the end-diastolic pressure/dimension relation was comparable between groups at baseline. Reperfusion was associated with a significant increase in diastolic stiffness compared to baseline in all groups $(P<.05$ by repeated-measures ANOVA; Figure 3 ); however, there were no significant group differences throughout reperfusion.

Plasma CK activity was similar in all groups at baseline and during arrest (BCP1-BCP4 in Figure 4). Plasma CK activity was significantly greater in the cold AL-BCP group versus $\mathrm{K}^{+}$-BCP at 60 minutes of reperfusion $(P=.002)$. However, there was no statistically significant difference in CK activity among groups at 120 minutes of reperfusion $(P=.17)$.
Postexperimental myocardial tissue water content was comparable among all groups $\left(\mathrm{K}^{+}-\mathrm{BCP}, 78.4 \% \pm 0.4 \%\right.$; warm AL-BCP, $78.6 \% \pm 0.2 \%$; cold AL-BCP, $77.7 \% \pm$ $0.2 \%$ ), and there was no significant difference from that in normal hearts $(\mathrm{n}=6)$ not subjected to cardioplegic arrest and CPB $(77.9 \% \pm 0.3 \% ; P=.15)$.

Myeloperoxidase activity was comparable between warm AL-BCP (10.0 \pm 1.1 absorbance units $/ \mathrm{min} / \mathrm{g})$ and $\mathrm{K}^{+}$-BCP $(7.4 \pm 1.1$ absorbance units $/ \mathrm{min} / \mathrm{g} ; P=.24)$. However, myeloperoxidase activity was significantly greater in cold AL-BCP $(20.3 \pm 2.1$ absorbance units/ $\mathrm{min} / \mathrm{g}$ ) when compared with both warm AL-BCP and $\mathrm{K}^{+}$BCP $(P<.001$ for both comparisons).

Postexperimental left anterior descending coronary artery endothelial function, quantified by the maximum endothelial-dependent vasorelaxation responses at the highest concentrations of acetylcholine $(690 \mathrm{nmol} / \mathrm{L})$ and endothelium-dependent receptor-independent calcium ionophore A23187 (380 nmol/L) used, was comparable among groups (Figure 5). Coronary vascular smooth muscle relaxation determined by the maximal response to sodium nitroprusside (190 nmol/L; Figure 5) was similarly comparable among groups. Therefore, postcardioplegia coronary vascular reactivity as a measure of endothelial function was comparably preserved in all groups.

\section{Discussion}

This study compared depolarized arrest using potassium against polarized arrest using the unique combination of adenosine and lidocaine in blood cardioplegia under hypothermia and normothermia. The time to complete arrest was prolonged with both hypothermic and normothermic ALBCP compared to potassium cardioplegia. However, postcardioplegia systolic function, diastolic stiffness, and overall global performance (PRSW) in hearts receiving either cold or warm AL-BCP were comparable to hypothermic $\mathrm{K}^{+}$-BCP. Neutrophil accumulation in myocardium was comparable in the warm AL-BCP and hypothermic $\mathrm{K}^{+}$$\mathrm{BCP}$ groups but was greater in the cold AL-BCP group. In addition, plasma CK release and coronary artery endothelial function were comparable among all groups. Therefore, postcardioplegia functional outcomes achieved with nondepolarizing AL-BCP were comparable to those of the standard cold $\mathrm{K}^{+}$-BCP. Furthermore, nondepolarizing arrest with intermittent AL-BCP can be used at normothermic temperatures, thereby avoiding the need for either profound hypothermia or continuous delivery of warm depolarizing $\mathrm{K}^{+}$-BCP formulations.

Hypothermia has been considered a cornerstone of myocardial protection. However, hypothermia has also been associated with deleterious changes in the myocardium. Contractile dysfunction, ${ }^{17}$ uncoupling of excitation-contraction mechanisms, edema, and calcium dyshomeostasis ${ }^{18}$ 
have been noted after rewarming from profound hypothermia. Recovery of LV systolic and diastolic performance has been shown to be decreased or delayed after arrest with cold cardioplegia ${ }^{19}$ compared with warm cardioplegia. Cold cardioplegia has been associated with more frequent perioperative infarctions and postoperative low-output syndrome. ${ }^{20}$ In this study, we did not observe any untoward effects of hypothermia in these normal canine ventricles compared with their normothermic AL-BCP counterparts. Future studies should compare the postcardioplegia function of ischemically injured ventricles to determine whether warm ALBCP can avoid the disadvantages of hypothermia.

Warm cardioplegia avoids the membrane instability and reduces the ion dyshomeostasis that is associated with hypothermia ${ }^{4}$ and has been advocated for better myocardial protection over cold cardioplegia. ${ }^{21}$ However, warm cardioplegia must be administered continuously or nearly continuously to avoid ischemia. The results from this study suggest that normothermia can be safely used even with intermittent delivery of cardioplegia solution when the heart is arrested in a polarized state by using adenosine and lidocaine as arresting agents. The study by Dobson and Jones ${ }^{9}$ suggests that the metabolic rate is dramatically reduced during polarized arrest with adenosine and lidocaine. The observation that postcardioplegia outcomes are comparable between the warm AL-BCP and cold $\mathrm{K}^{+}$-BCP groups is consistent with this notion.

The delay in arrest with AL-BCP contrasts with the rapid arrest observed with crystalloid AL-BCP reported by Dobson and Jones ${ }^{9}$ in an isolated perfused rat heart preparation. The concentration of adenosine may have been suboptimal for the canine myocardium. The concentration of adenosine (400 $\mu \mathrm{mol} / \mathrm{L}$ ) was limited by the high concentration of adenosine needed in the crystalloid concentrate to achieve target concentrations in 22:1 blood cardioplegia, and by the maximum pump delivery configuration of the cardioplegia delivery system. While the concentration of adenosine was twofold higher than Dobson and Jones' crystalloid cardioplegia $(0.2 \mathrm{mmol} / \mathrm{L}),{ }^{9}$ it was less than $5 \%$ of the maximum concentrations employed by Schubert and colleagues ${ }^{22}$ (20 $\mathrm{mmol} / \mathrm{L})$ and Boehm and associates ${ }^{23}(10 \mathrm{mmol} / \mathrm{L})$. The intravascular concentration of adenosine may have been rapidly reduced by adenosine deaminase in the interim between infusions. In addition, the failure of hypothermic AL-BCP to achieve complete quiescence may be related to lidocaine's sensitivity to temperature; lidocaine fails to maintain the membrane potential at the resting value under profound hypothermia $\left(10^{\circ} \mathrm{C}\right) .{ }^{24}$ This temperature sensitivity is specific for lidocaine because the prototype $\mathrm{Na}^{+}$ channel blocker tetrodotoxin does not show such temperature dependence. ${ }^{5}$ Therefore, lidocaine may be more effective at normothermic or tepid temperatures, which is con- sistent with the superior arrest achieved with normothermic AL-BCP observed in this study.

Neutrophil accumulation was paradoxically greater in the cold AL-BCP group, despite similar functional recovery at the end of reperfusion. It is unlikely that the increased neutrophil accumulation is representative of a proinflammatory effect of adenosine mediated by $\mathrm{A}_{1}$-receptor activation, because the counterbalancing anti-inflammatory effects mediated by $\mathrm{A}_{2}$-receptor activation are more potent. In any event, the increased neutrophil accumulation in cold ALBCP did not adversely affect postcardioplegia contractile or coronary artery endothelial function. This finding may suggest that neutrophils do not play a major role in postischemic contractile function, as has been reported in other models of ischemic and reperfused myocardium. ${ }^{25}$

Lidocaine was removed from the terminal blood cardioplegia to reduce the total systemic lidocaine load and to avoid potential lidocaine toxicity. The removal of lidocaine was associated with reanimation of the heart, thus emphasizing the need for simultaneous delivery of both agents in combination to achieve cardioplegia. However, reanimation during infusion of terminal blood cardioplegia should not be problematic because the oxygen requirements of the vented heart are supported by delivery of blood. Accordingly, reanimation of the myocardium during the terminal cardioplegia phase did not adversely affect ventricular or endothelial function. Additionally, cardiac motion during the terminal infusion is not likely to interrupt the surgical procedure, because only proximal anastomoses are being constructed or all anastomoses have already been completed if performed under a single crossclamp. Whether resumption of electromechanical activity during terminal cardioplegia is tolerated in ischemically injured hearts in which cardioplegia plays a resuscitative role should be determined by further experiments with appropriate models.

In conclusion, normothermic depolarized arrest with ALBCP may have advantages over hyperkalemic depolarizing cardioplegia in protecting the heart during chemical arrest. Future studies are warranted to elucidate the mechanisms of protection with depolarized arrest versus the gold standard potassium depolarized arrest in more challenging models of cardiac surgery, such as surgical reperfusion of ischemically injured myocardium, prolonged crossclamp times, or prolonged storage for transplantation. In addition, future studies on AL-BCP should quantify postcardioplegia arrhythmias, because adenosine has potent inhibitory effects on ventricular fibrillation ${ }^{26}$ mediated by an $A_{1}$ receptor mechanism. Finally, future studies should optimize the dose of adenosine in blood cardioplegia. The concentration used in the present study was $20 \%$ of the highest dose $(2 \mathrm{mmol} / \mathrm{L})$ reported by Mentzer and colleagues using adenosine in hyperkalemic blood cardioplegia in humans ${ }^{27}$; hence, 
higher doses of adenosine than used in the present study may facilitate more rapid arrest.

\section{References}

1. Lopez JR, Jahangir R, Jahangir A, Shen WK, Terzic A. Potassium channel openers prevent potassium-induced calcium loading of cardiac cells: possible implications in cardioplegia. J Thorac Cardiovasc Surg. 1996;112:820-31.

2. Damiano RJ Jr. The electrophysiology of ischemia and cardioplegia: implications for myocardial protection. J Card Surg. 1995;10(4 suppl): 445-53.

3. Weisel RD, Mickle DA, Finkle CD, Tumiati LC, Madonik MM, Ivanov J. Delayed myocardial metabolic recovery after blood cardioplegia. Ann Thorac Surg. 1989;48:503-7.

4. Sakai T, Kuihara S. Effect of rapid cooling on the mechanical and electrical responses in ventricular muscle of the guinea pig. $J$ Physiol (Lond). 1985;361:361-78.

5. Chambers DJ. Polarization and myocardial protection. Curr Opin Cardiol. 1999; 14:495-500.

6. Maskal SL, Cohen NM, Hsia PW, Wechsler AS, Damiano RJ Jr. Hyperpolarized cardiac arrest with a potassium-channel opener, aprikalim. J Thorac Cardiovasc Surg. 1995;110:1083-95.

7. Jaywant AM, Stephenson ER, Matte GS, Prophet GA, LaNoue KF, Griffith JW, et al. Potassium-channel opener cardioplegia is superior to St. Thomas' Solution in the intact animal. Ann Thorac Surg. 1999;68: 67-74.

8. Chi L, Uprichard AC, Lucchesi BR. Profibrillatory actions of pinacidil in a conscious canine model of sudden coronary death. J Cardiovasc Pharmacol. 1990;15:452-64.

9. Dobson GP, Jones MW. Adenosine and lidocaine: a new concept in nondepolarizing surgical myocardial arrest, protection, and preservation. J Thorac Cardiovasc Surg. 2004;127:794-805.

10. Belardinelli L, Linden J, Berne RM. The cardiac effects of adenosine. Prog Cardiovasc Dis. 1989;32:73-97.

11. Auchampach JA, Gross GJ. Adenosine A1 receptors, KATP channels, and ischemic preconditioning in dogs. Am J Physiol. 1993;264(5 Pt 2):H1327-36.

12. Vinten-Johansen J, Dobson GP, Corvera JS. Polarized arrest with adenosine-lidocaine blood cardioplegia: a new paradigm in myocardial protection [abstract]. J Mol Cell Cardiol. 2003;35:A7.

13. Thourani VH, Ronson RS, Van Wylen DGL, Shearer ST, Katzmark SL, Zhao Z-Q, et al. Adenosine-supplemented blood cardioplegia attenuates postischemic dysfunction after severe regional ischemia. Circulation. 1999;100(suppl 2):II376-83.
14. Velez DA, Morris CD, Budde JM, Muraki S, Otto RN, Guyton RA, et al. All blood (miniplegia) versus dilute cardioplegia in experimental surgical revascularization of evolving infarction. Circulation. 2001; 104(Suppl 1):I296-306.

15. Nakamura M, Thourani VH, Ronson RS, Velez DA, Ma X-L, Katzmark S, et al. Glutathione reverses endothelial damage from peroxynitrite, the by-product of nitric oxide degradation, in crystalloid cardioplegia. Circulation. 2000;102(Suppl):332-8.

16. Mullane KM, Kraemer R, Smith B. Myeloperoxidase activity as a quantitative assessment of neutrophil infiltration into ischemic myocardium. J Pharmacol Methods. 1985;14:157-67.

17. Tveita T, Skandfer M, Refsum H, Ytrehus K. Experimental hypothermia and rewarming: changes in mechanical function and metabolism of rat hearts. J Appl Physiol. 1996;80:291-7.

18. Navas JP, Anderson W, Marsh JD. Hypothermia increases calcium content of hypoxic myocytes. Am J Physiol. 1990;259(2 Pt 2):H333-9.

19. Yau TM, Ikonomidis JS, Weisel RD, Mickle DA, Ivanov J, Mohabeer MK, et al. Ventricular function after normothermic versus hypothermic cardioplegia. J Thorac Cardiovasc Surg. 1993;105:833-43; discussion 843-4.

20. Yau TM, Weisel RD, Mickle DA, Komeda M, Ivanov J, Carson S, et al. Alternative techniques of cardioplegia. Circulation. 1992;86:II377-84.

21. Rosenkranz ER, Vinten-Johansen J, Buckberg GD, Okamoto F, Edwards H, Bugyi H. Benefits of normothermic induction of blood cardioplegia in energy-depleted hearts, with maintenance of arrest by multidose cold blood cardioplegic infusions. J Thorac Cardiovasc Surg. 1982;84:667-77.

22. Schubert T, Vetter H, Owen P, Reichart B, Opie LH. Adenosine cardioplegia: adenosine versus potassium cardioplegia-effects on cardiac arrest and postischemic recovery in the isolated rat heart. J Thorac Cardiovasc Surg. 1989;98:1057-65.

23. Boehm DH, Human PA, von Oppell U, Owen P, Reichenspurner H, Opie LH, et al. Adenosine cardioplegia: reducing reperfusion injury of the ischaemic myocardium? Eur J Cardiothorac Surg. 1991;5:542-5.

24. Makielski JC, Falleroni MJ. Temperature dependence of sodium current block by lidocaine in cardiac Purkinje cells. Am J Physiol (Heart Circ Physiol). 1991;260:H681-9.

25. Sato H, Jordan JE, Zhao Z-Q, Sarvotham SS, Vinten-Johansen J. Gradual reperfusion reduces infarct size and endothelial injury but augments neutrophil accumulation. Ann Thorac Surg. 1997;64:1099107.

26. Wainwright CL, Parratt JR. An antiarrhythmic effect of adenosine during myocardial ischemia and reperfusion. Eur J Pharmacol. 1988; 145:183-194.

27. Mentzer RM, Jr, Birjiniuk V, Khuri S, Lowe JE, Rahko PS, Weisel $\mathrm{RD}$, et al. Adenosine myocardial protection. Preliminary results of a Phase II clinical trial. Ann Surg. 1999;229:643-50. 